NBER WORKING PAPER SERIES

\title{
INADEQUACY OF NATION-BASED AND VAR-BASED SAFETY NETS IN THE EUROPEAN UNION
}

\author{
Edward J. Kane \\ Working Paper 12170 \\ http://www.nber.org/papers/w12170
}

\section{NATIONAL BUREAU OF ECONOMIC RESEARCH 1050 Massachusetts Avenue Cambridge, MA 02138 \\ April 2006}

The author wishes to thank Richard C. Aspinwall for many helpful suggestions. The views expressed herein are those of the author(s) and do not necessarily reflect the views of the National Bureau of Economic Research.

(C2006 by Edward J. Kane. All rights reserved. Short sections of text, not to exceed two paragraphs, may be quoted without explicit permission provided that full credit, including $\odot$ notice, is given to the source. 
Inadequacy of Nation-Based and VaR-Based Safety Nets in the European Union Edward J. Kane

NBER Working Paper No. 12170

April 2006, Revised July 2006

JEL No. G21, G28, P51

\begin{abstract}
Considered as a social contract, a financial safety net imposes duties and confers rights on different sectors of the economy. Within a nation, elements of incompleteness inherent in this contract generate principal-agent conflicts that are mitigated by formal agreements, norms, laws, and the principle of democratic accountability. Across nations, additional gaps emerge that are hard to bridge. This paper shows that nationalistic biases and leeway in principles used to measure value-atrisk and bank capital make it unlikely that the crisis-prevention and crisis-resolution schemes incorporated in Basel II and EU Directives could allocate losses imbedded in troubled institutions efficiently or fairly across member nations.
\end{abstract}

Edward J. Kane

Department of Finance

Boston College

Chestnut Hill, MA 02467

edward.kane@bc.edu 
June 19, 2006

\section{Inadequacy of nation-based and VaR-based safety nets in the European Union}

Considered as a social contract, a financial safety net imposes duties and confers rights on different sectors of the economy. Within a nation, elements of incompleteness inherent in this contract generate principal-agent conflicts that are mitigated by formal agreements, norms, laws, and the principle of democratic accountability. Across nations, additional gaps emerge that are hard to bridge. This paper shows that nationalistic biases and leeway in principles used to measure value-at-risk and bank capital make it unlikely that the crisis-prevention and crisis-resolution schemes incorporated in Basel II and EU Directives could allocate losses imbedded in troubled institutions efficiently or fairly across member nations.

\section{Introduction}

Almost 250 years ago, Adam Smith (1759, p. 263) called mankind's capacity for self-delusion the “source of half the disorders of human life.” In modern times, psychological experiments have repeatedly confirmed the importance of this capacity (e.g., Tversky and Kahneman, 1974 and 1981). Today, it is well understood that the human mind exhibits an emotion-based propensity to hold firm to comforting beliefs. It does so by embracing evidence that reinforces cherished judgments and neglecting, rejecting, or repressing evidence that would generate cognitive dissonance.

In the European Union (EU), the presumed adequacy of nation-based and VaR-based banking safety nets is rooted in a series of convenient, but irrational beliefs. These beliefs have been strongly reinforced by lobbying interests and buttressed by research funding and other economic benefits made available to empirical financial researchers able to affirm (i.e., not reject) statistical hypotheses consistent with these beliefs.

Behavioral finance presumes that a distaste for cognitive dissonance prevents investors from forming their expectations rationally and subjects asset prices to fads. But if one grants that investor expectations can be manipulated, it is hard to resist the hypothesis that policymakers' expectations can be manipulated as well (Zajac, 2006). In group or committee settings, individual self-deceit becomes a 
policymaking bias when the forum within which decisions are made imposes implicit or explicit reputational penalties on members that raise discomforting concerns.

Particularly in choosing standards and procedures for supervising banks, policymakers are subjected to intense and unrelenting lobbying pressure. Herding occurs when regulated institutions exploit officials' cognitive biases to undermine regulatory constraints. Whatever other levers lobbyists might manipulate, they urge policymakers to adopt self-servingly parsimonious models of how markets work and to neglect the consequences of low-probability events for which these well-lobbied models are likely to prove inadequate.

Section 2 of this paper explains self-serving lobbying activity as part and parcel of the idea that a financial safety-net is an incomplete social contract. Contract terms define responsibilities for crisis prevention and loss absorption. At the moment, substantial gaps in these responsibilities can be found in the European safety net. Section 3 introduces the concept of Value at Risk (VaR) and argues that as financial institutions and markets increasingly overleap national borders, VaR estimates of the loss exposure of conglomerate firms become less trustworthy and limitations of national systems of regulation become more consequential.

Section 4 critiques the Basel approach to capital budgeting. VaR was incorporated into the 1996 Market Risk Amendment to Basel I and VaR-like models have been partially incorporated into the Basel II treatment of credit risk. Section 5 argues that, both in the European Union's Ecofin Council and in the Basel Committee on Banking Supervision, authorities are either fooling themselves or fooling their constituents about the reliability of accounting measures of bank capital and risk exposure and about the adequacy of the essentially improvisational crisis-prevention and crisis-resolution responsibilities that currently constitute the EU's financial safety net. If confronted with one or more large-bank insolvencies, nationalistic pressures on home and host regulators are bound to aggravate weaknesses in accounting reports and to prevent the losses imbedded in deeply troubled institutions from being allocated quickly, efficiently, or fairly across the member nations involved. Sections 6 and 7 discuss how cross-country gaps in supervisory accountability might be bridged. 


\section{Incomplete rights and duties conferred by financial safety nets}

It is instructive to conceive of a financial safety net as a social contract. The contract's counterparties are major sectors of a political and economic community: taxpayers, financial institutions; household and business borrowers; depositors; investors; regulators; and elected officials.

By its nature as a contract, the net imposes duties on and confers rights to its counterparties. The contract is incomplete in two ways. First, it does not enumerate a set of observable events that trigger netrelated rights and duties. Second, it does not spell out relevant rights and duties in an enforceable way. Instead, safety-net arrangements empower specific regulatory agents to decide these issues improvisationally and under great pressure. Time available for making these decisions is compressed by market forces, while each agent's scope for cooperative improvisation is limited by gaps in information flows, by administrative law, and by the workings of democratic accountability.

Every safety-net contract itself may be divided into three segments. One segment assigns particular supervisory officials responsibility for preventing disruptive financial-institution insolvencies. Supporting statutes empower these officials to manipulate a specific array of policy instruments in furtherance of this goal. A second contract segment defines a range of tax-transfer techniques for financing this supervisory activity. These techniques include user fees and a method for allocating across society whatever losses officials fail to prevent. The final segment of the social contract dictates the economic and political incentives under which the operators of the net discharge their responsibilities. ${ }^{1}$

In any given country, instruments for preventing individual-institution insolvencies are imbedded in that country's supervisory arrangements, disclosure regime, and lender-of-last-resort powers. Loss absorption and transfer abilities align the value of explicit and implicit guarantees of private obligations with the sum of two items: (1) fees that can be collected from guaranteed parties, and (2) contingent contributions that can be extracted from taxpayers when user fees and supplemental assessments from regulated institutions fail to cover the safety net's bills.

\footnotetext{
${ }^{1}$ The surging economic insolvency of the U.S. Pension Benefits Guarantee Corporation illustrates how quickly costs can expand when safety-net managers have no prevention power and no authority to allocate losses directly.
} 
The activities of safety-net operators produce and allocate a series of implicit and explicit net subsidies and burdens across the net's counterparty sectors. An individual sector's place in the flow of subsidies and burdens depends both on its political clout and on the path of events. Difficulties in observing implicit revenues and costs make differences in analytic capacity consequential. Savvy sectors and subsectors can turn defects in the accountability of individual regulators to their advantage. It pays better-informed and better-connected individuals to leverage their advantage by accumulating and exercising political clout. Less well-connected and poorly informed individuals can neither easily observe nor easily counter the pressures by which safety-net officials are dissuaded from executing their assignments with appropriate speed, fairness, and efficiency.

\subsection{Additional incompleteness in the EU Net}

For institutions operating in more than one member state, EU Directives assign home-country regulators responsibility for consolidated oversight and make host-country regulators responsible both for supervising operations within the borders of the host country and for sharing relevant information with home-country officials. However, in the event of a multinational bank's insolvency, the 1994 Directive on Deposit-Guarantee Schemes establishes a minimum insured amount of 20,000 euros and makes host countries responsible for paying off depositors of foreign-bank subsidiaries chartered by their jurisdiction. $^{2}$

The result is that contractual arrangements for coordinating supervisory and tax-transfer activity across EU countries produce additional gaps that expand the range of incentive conflicts. First, supervisors in any one member country (say, country A) cannot observe in timely fashion the implicit aggregate damages that poor regulatory systems or performance in another Country (B) might visit upon their citizenry. Second, supervisors in Country A lack the authority to make anyone in the foreign

\footnotetext{
${ }^{2}$ Branch offices may raise their coverage to the level of the host country by joining its deposit-insurance scheme (Huizenga, 2005).
} 
Country B compensate Country A for the losses in welfare that B's substandard regulatory systems or behavior might cause citizens in A.

EU ministers promote the comforting view that these additional sources of safety-net incompleteness are externalities that sincere regulators in different countries will acknowledge and speedily eliminate if a crisis were to threaten. But economic theory and experience in assigning losses in real-world corporate and deposit-insurance insolvencies do not support a portrait of scruples-driven cooperation in conflicted circumstances. It is unreasonable to believe that improvisational cooperation will flourish at times when it runs strongly against the national interests of one or more partner countries.

Around the world, opportunistic creditors supply collateralized loans or guarantees to troubled firms that want new funding merely to postpone the accounting recognition of an existing economic insolvency. When we say that troubled firms lack capital, we mean that the economic value of their assets is less than the economic value of their liabilities. This need not mean that they lack good collateral. Suppliers of liquidity to failing firms (including national lenders of last resort) act as predatory lenders if they look forward -- not to an advantageous repayment of their loans -- but to taking title to the collateralized assets in an anticipated borrower default. Such asset stripping lets a predatory lender extract profits by enlarging the losses of the firm's uncollateralized lenders and guarantors. Because predatory intent is hard to prove, lawsuits seeking to recoup damages from lenders that deepen an underwater firm's insolvency in this way are seldom successful.

Unless national officials are constrained by cross-country agreements that can be enforced in neutral or international courts, democratic accountability would dispose them in a financial crisis to favor policy options that furnish similar combinations of liquidity and accounting relief to fellow citizens at the expense of creditors and taxpayers in foreign lands. For this reason, the EU would benefit as a community if it could negotiate an explicit and enforceable agreement designed to identify and resolve the incentive conflicts that inevitably arise in an actual crisis. At a minimum, a workable cross-country agreement would have to define what would constitute negligence or misfeasance by safety-net officials and make 
individual governments responsible for economic damages that regulatory misbehavior visits on other countries.

\section{Weaknesses in VaR-based supervision}

Representatives from various countries are helping to redesign a system of risk-based capital requirements known as "Basel I" (Basel Committee, 2003). This system neglects the foundational issue of how to verify and share information about financial firms across countries. Draft provisions of the new system (called Basel II) focus on how to use whatever data are being shared to allocate accounting measures of a conglomerate institution's capital and diversification benefits between local and foreigncountry exposures to insolvency risk. Although a huge literature exists on the costs and benefits generated for the EU by the evolving Basel Framework (e.g., Dermine, 2003; Garcia and Nieto, 2006; Herring and Schuermann, 2006; Schoenmaker and Osterloo, 2004 and 2005; Schüler, 2003; Vives, 2001), the need to mitigate or overcome bankers' and foreign regulators' incentives to hide embarrassing information is not receiving the analysis it deserves.

A statistical concept called "Value at Risk" (VaR) serves as the conceptual foundation for the supervisory risk-measurement, risk-budgeting, and stress-testing activities the Advanced Internal Ratings based (IRB) version of Basel II contemplates. VaR is defined as the maximum potential loss in an institution's net portfolio value (NW) that can occur over a specific horizon (e.g., two weeks) at a specified level of statistical confidence (e.g., 99\%). In practice, VaR can only be calculated by assuming a series of unverifiable facts about the observability of an institution's true NW and about the nature of the unknown probability distributions that govern the institution's risks and returns over alternative future horizons.

In statistical terms, VaR asks managers and regulators to estimate the negative "tail" of each institution's unknowable distribution of future returns and to locate a "quantile" in this distribution whose chance of occurrence is remote enough to neglect. Viewed from a contracting perspective, VaR-based 
supervision uses quasi-reproducible statistical methods to calculate a threshold of stockholder-contributed risk support beyond which other sectors of society are expected to cover losses.

It is easy to understand why VaR appeals to policymakers and why its implicit endorsement in the so-called "advanced" Basel system has turned it into the de facto standard for assessing institutional exposure. As a single number, its implications are easy to understand. It purports to quantify the risk in each institution's portfolio in a putatively reproducible way, no matter how complex the interactions among asset and liability positions might be.

However, VaR's quasi-reproducibility is purchased at the cost of making it depend on a number of unlikely assumptions. The potential wishfulness of the assumptions embodied in its bare-bones calculation impair VaR's ability to track the response of institutional risk-taking to the changing character of incentive conflicts and other signal events.

1. Sincerity. The single most-dangerous assumption is to suppose that individual banks would not calculate and implement $\mathrm{VaR}$ opportunistically. This convenient assumption relieves supervisors of responsibility for modeling how predictable bureaucratic delays in discovering and responding strongly to capital weakness might affect bank portfolio decisions and alter the usefulness of VaR calculations. Opportunistic banks can extract safety-net subsidies by understating loss probabilities and building portfolios that locate heavy loss exposures just beyond the maximum probability of default specified by the regulatory $\mathrm{VaR}$. Aggressive banks can also generate additional subsidies by locating heavy loss exposures either intraday or outside the multiday time horizon specified in the regulatory VaR calculation.

2. Quasi-Stationarity of Daily Returns. A stationary distribution is one whose mean and shape does not change with the passage of time. Data that are directly available from bank records tend to be sparse, badly measured, and nonstationary. In looking back in time to create a sample of usable data from past returns and in extrapolating past experience forward, it is necessary to relax the stationarity assumption to 
allow for exogenous jumps and policy-driven shifts in the return distribution. In making these allowances, the methods used by an institution's quants inevitably fall short of objective reproducibility.

The first step in calculating VaR is to construct model-based estimates of the market value of designated portfolio positions (ideally this would include an institution's credit and operational exposures) and to consolidate changes in these values into a database of daily returns. To turn this database into a sample from which a quasi-stationary probability distribution of future returns can be estimated reliably requires analysts to make decisions about how to blend data from different eras into a sample large enough to estimate closely the shape and parameters of a putative distribution of past returns: $f(R)$. Typically, this blending entails smoothing an institution's historical data to reflect the timing of important market events and known changes in portfolio strategy. Assuming smoothing adjustments are made sincerely and skillfully, the adjusted frequency distribution, $f(R)$ may be treated as an estimate of the baseline distribution of future daily returns: $f^{*}(R)$. However, econometric tests and common sense indicate that unforeseeable information flows can change the true distribution of future returns sharply and suddenly. Even if the likely distribution $f^{*}(R)$ were closely estimated, the value of its means, standard deviations, and correlations would not be stationary. They are bound to change with innovations in bank strategy and unpredictable "jump shifts."

3. Independence of Daily Returns. The simplest way to transform the daily return distribution into a distribution that covers the intended VaR horizon is to assume counterfactually that each day of the longer period constitutes a statistically independent draw from $f^{*}(R)$. Until ways to model serial correlation are standardized, each institution's quants remain free to represent the effects of the non-independence of successive returns in ad hoc ways.

4. Non-optionality of Contract Returns. The value of bank loan and deposit contracts includes various imbedded options, whose value varies with bank behavior and with market interest rates. At its option, a bank may follow market movements in interest rates on loans and deposits more or less fully and at 
different speeds. At their option, customers may respond to differences between contract and market interest rates by incurring the cost of prepaying loans, by making early withdrawals from term deposits, or by drawing down credit lines. This leaves different institutions free to estimate in nonstandard and nontransparent ways how the changing value of these options affects enterprise returns.

Summary. Basel II neglects an institution's strategic incentives to manipulate VaR-based estimates of regulatory capital to reduce their usefulness to regulators. The over-riding criterion of statistical robustness demands that numerous ad hoc adaptations be made in the method's baseline assumptions of stationarity, independence, and non-optionality before VaR can be interpreted in a forward-looking manner. Regulators lack the ability to verify that these adaptations are made in an unbaised manner. ${ }^{3}$ Because VaR is favored by regulators despite its flaws, users must understand that state-of-the-art VaR calculations do not in fact reliably predict the maximum loss an institution can experience over a given time interval at a specified probability. This is because:

- VaR does not incorporate the size of the loss exposures and penalties that arise when the bound it defines is breached;

- VaR is not sensitive to breaches that occur intraday or in periods beyond those spanned by the chosen horizon;

- The usefulness of VaR calculations declines in times when underlying parameters (such as market volatility) fluctuate sharply;

- In changing environments, the data needed to estimate VaR cannot reliably be constructed in a truly reproducible manner from a bank's historical records.

\section{Weaknesses in Basel's building-block approach to risk budgeting}

\footnotetext{
${ }^{3}$ Paul Kupiec and James O’Brien (1997) proposed a scheme designed to penalize incompetent or low-ball estmates, but authorities did not take their scheme beyond an experimental stage.
} 
In Basel I and in the standardized version of Basel II, the risk support (R) needed for an institution's portfolio of $\mathrm{n}$ positions is defined as the weighted sum of the risk support $\left(W_{i}\right)$ required for each component asset or liability position $\left(X_{i}, i=1, \ldots, n\right)$. Calculations assign an incremental risk weight $\left(w_{i}\right)$ to each of the $\underline{n}$ building-block positions, so that:

$$
R=\sum_{i=1}^{n} W_{i}=\sum_{i=1}^{n} w_{i} X_{i}
$$

In the formulas used in Basel I, most liabilities are not weighted and the weights assigned to asset building blocks lie in the interval between zero and one.

Whether or not used in conjunction with $\mathrm{VaR}$, equation (1) imposes numerous unlikely, but convenient restraints on the underlying model of risk generation. The most dangerous of these assumptions is to model the need for risk support as homogeneous of degree one in the building-block positions $X_{i}$.

Two biases are generated by not linking building-block measures of risk to the actual level of an institution's economic capital. The first bias is that, other things equal, safety-net subsidies increase when a protected firm's stockholder-contributed capital declines and, at the margin, the value of safety-net subsidies can be intensified by concentrating rather than diversifying individual-position risk. Dangl and Lehar (2000) show that VaR-based capital requirements cannot prevent banks from expanding their loss exposures when they are in distress. The second problem is that the degree to which accounting net worth overstates economic capital tends to increase when and as the economic capital of a firm protected by the safety net slips toward the danger zone. These biases mean that for a poorly capitalized bank-- the kind regulators most need to worry about --Basel capital requirements severely understate its need for capital.

Economic capital is the sum of tangible and intangible net worth. The great innovation of the system of prompt corrective action established in the U.S. by the Federal Deposit Insurance Corporation Improvement Act of 1991 (FDICIA) is that it dictates a nonzero (2-percent) tangible-capital threshold for failing a troubled bank. Although the economic value of tangible positions is typically exhausted by the 
time book values decline to this level, offsetting intangible net worth may still exist. As long as the value of the sum of a bank's tangible and intangible assets is positive, last-ditch gambles for resurrection are less rewarding. In most cases, as tangible insolvency slides towards the 2-percent threshold, stockholder interest in maintaining their claim to the value of intangible going-concern assets directs managers to seek to rebuild tangible capital or to negotiate a voluntary merger.

\subsection{Returns to scale and scope in risk-bearing capacity}

Equation (1) neglects the strong possibility that at least some financial institutions enjoy economies of scale and scope in taking or diversifying risk. Equation (1) presumes that, irrespective of the value of an institution's asset size or net worth, each building block's average and marginal contributions to enterprise risk are: (a) the same and (b) independent of the riskiness of other positions.

In symbols:

$$
\begin{gathered}
\frac{\partial \mathrm{R}}{\partial \mathrm{X}_{\mathrm{i}}}=w_{i} \\
\frac{\partial}{\partial \mathrm{X}_{\mathrm{j}}}\left(\frac{\partial \mathrm{R}}{\partial \mathrm{X}_{\mathrm{i}}}\right)=0 .
\end{gathered}
$$

The lack of conditionality in both assumptions is inconsistent with stockholders' limited liability, with mean-variance portfolio theory, and with empirical evidence. It is well-known that the marginal costs of transacting in derivatives fall with aggregate portfolio size and that the incremental stockholder value that a safety-net-protected firm might accrue from hedging or diversifying a concentrated risk exposure becomes negative as the value of enterprise-contributed capital approaches and passes through zero.

It is instructive to view Equation (1) as a production function whose output is $R$ and whose inputs are the portfolio building blocks $X_{i}$. Because of economics of scale in hedging and diversifying risk (including business risk), this function should show decreasing returns to scale for a well-diversified firm that has a substantial amount of economic net worth. This means that the marginal contribution $\frac{\partial R}{\partial X_{i}}$ of 
an expansion in each individual risky position $X_{i}$ would likely lie below its average contribution. For such firms, expanding all risky positions in the same proportion $(\lambda>0)$, increases $R$ to $\lambda^{h} R$, where $h$ is positive and less than one.

If the capital requirement $w_{i}$ for each building block $i$ is set at its marginal risk product, the total risk that enterprise capital needs to cover would exceed the formula-based requirement. It is reasonable to assume that political agreements hammered out at Basel would define marginal risk weights $w_{i}$ that would at the time seem appropriate for a bank whose size and capitalization are "representative" of the universe of internationally active banks. Hence, even this temporarily representative bank's total need for capital support could be greater than that generated by (1), even allowing for the formula's failure to include risk-reductions from any applicable hedging and diversifying activity. This helps to explain why observed capital positions have proved well in excess of Basel requirements.

\section{Cross-country gaps in VaR-based capital requirements}

VaR purports to measure the minimum amount of ownership capital that an individual institution needs to prevent its chance of becoming insolvent from exceeding a specific probability (say $p=.05$ ). It does not measure either of the two items that democratic accountability should require EU supervisors to manage: (1) the probable size of the losses that EU safety nets would have to absorb if the institution's capital were exhausted; and (2) how, in the event of a large bank's failure, safety-net losses would be shared across the various countries in which the insolvent institution had been operating.

Europe is an intricate mosaic of overlapping languages, native and immigrant communities, and nation-states. Supervisors' difficulties in observing insolvency (vision problems) and political and commercial advantages that they can accrue from not fully enforcing capital requirements (forbearance pressures) increase as an institution slides toward insolvency. Supervisory incentives to compensate for 
vision problems and to overcome forbearance pressures vary across countries with differences in cultural norms and regulatory systems.

To confront its heterogeneous elements, the EU needs an arrangement for holding each country's regulators accountable today for the expected long-run costs that weaknesses in their enforcement of capital requirements impose on other countries. To be viable, cross-EU supervisory agreements must confront and restructure the rights that nationally oriented political norms convey to home and host regulators:

1. The Nationalism Norm: Every regulator has a right to help domestic institutions to compete more effectively with foreign firms.

2. The Mercy Norm: Every regulator has a right to be merciful to domestic institutions whose weakness traces either to bad luck or poor judgment; only dishonest acts must be treated severely.

3. The Non-escalation Norm: Every regulator has a right to avoid actions that run a non-neglible risk of turning the insolvency of a particular firm or economic sector into a national financial disaster.

\subsection{Baseline numerical model of gaps in the observability of VaR}

To show how cross-country defects in enforcement incentives and vision interact in a VaR-based system, it is helpful to model risk-shifting opportunities at a bank that might be regarded as too big to fail and unwind (TBFU). The model underscores the challenges that emerge in supervising a large multinational bank holding company that operates legally separate bank subsidiaries in a home and host country. The host country may be conceived as the aggregate of other EU members. Both countries use the 5-percent VaR to set minimum capital requirements. ${ }^{4}$

The model assumes that bank managers recognize the value to their stockholders of parking a heavy loss exposure just beyond each bank's regulatory VaR. Each bank holds a \$1,000 billion portfolio

\footnotetext{
${ }^{4}$ Regulatory VaRs are much more conservative than this. The same qualitative policy implications would emerge if we were to multiply loss exposures by 10 and cut the VaR to a more-realistic 0.5 percent.
} 
of one-period loans whose contract rate is 8 percent. Returns on the individual-bank portfolios are uncorrelated. On each portfolio, the probability of default is 4 percent and the "loss given default" (LGD) is $\$ 1$ trillion. ${ }^{5}$

The binomial probability distribution of returns for each bank is summarized in Table 1. Each bank's 5-percent VaR is zero. If each bank holds no capital (i.e., finances itself entirely with deposits) and we conveniently assume that deposit funding is free, expected returns may be calculated as: .96(80) $.04(1,000)=\$ 76.8-40=\$ 36.8$ billion.

Each example assumes that explicit deposit-insurance premia are zero, but introduces differences in implicit premia (i.e., in supervisory burdens). The analysis explores how agency problems differ between home and host regulators and how defects in bank transparency and differences in regulatory systems might prevent nation-based requirements for capital from being adequate from a global point of view.

To explore the global consequences of the conglomerate's loss exposures, it is convenient to pretend that an EU Deposit Insurance Corporation (EUDIC) would be formed as a bailout mechanism that would take control of country deposit-insurance reserves and cover potential depositor losses in both countries. Table 2 states the distribution of liability transfers facing this hypothetical EUDIC. Its probability distribution of transfers is trinomial. The probability corresponding to the variate value at which EUDIC outpayments start is: $1-(.96)^{2}=.0784$ and the 5-percent VaR for the EUDIC is $-\$ 1,000$ billion. Although the 5-percent Var is supported in each country taken separately, the conglomerate's global 5-percent VaR is not. The result is that the EUDIC has the following expected outpayment (in billions):

$$
\mathrm{E}_{\mathrm{EUDIC}}=0+.0768(-\$ 1,000)+.0016(-\$ 2,000)=-\$ 80 \text {. }
$$

Relative to bank profits, the EUDIC's expected outpayment seems far too large to be economically efficient.

\footnotetext{
${ }^{5}$ Though unrealistic, it is very convenient numerically to set the LGD equal to 100 percent of asset value.
} 
To control cross-country risk shifting, the Basel agreement tasks the home-country regulator with supervising the consolidated enterprise. Table 3 states the probability distribution for the conglomerate holding company.

Effects on the EDUIC depend on the transparency of bank and regulatory activity. If the parent regulator is fully informed of the parent's foreign exposure, it would recognize that the conglomerate's 5percent VaR is $\$ 920$ billion and require it to hold this amount of capital.

\subsection{Dual sources of non-transparency}

With asymmetric information, the EUDIC's loss exposure would be increased in either of two circumstances:

(1) If either or both banks under-report their loss exposure to their chartering authority;

(2) If either or both regulators under-report the loss exposures they observe to counterpart regulators in the other country.

Under-Reporting by Both Banks. Let us suppose that both banks under-report the probability of loss (p) and the loss given default (LGD) by one-half. In that case, the host regulator's VaR-based capital requirement would be zero and the home-country regulator would respond to the conglomerate probability shown in Table 5. The host-country regulator enforces a zero capital requirement and the EUDIC again faces the distribution of outpayments shown in Table 2.

Under-Reporting by Host Regulator Only. Now let us suppose that the host regulator cooperates with the foreign sub in misinforming parent managers and the home regulator to the same numerical degree. The conglomerate's perceived probability distribution is given in Table 6. Because the perceived distribution looks more favorable than the true distribution displayed in Table 3, the VaR is only $\$ 460$ billion. The distribution of EUDIC outpayments shown in Table 7 is worse than that in Table 4. Of course, parent managers do not want to be fooled and would have corporate controls in place that would ferret out this information eventually.

Under-Reporting by Parent Company and/or Home Regulator. Agency problems are more acute if transparency and enforcement break down in the home country. Host countries and the EUDIC have no 
regulatory authority over the parent corporation and no formal way to observe and influence the behavior of home-country regulators. They must rely on the parent and home regulator both to determine VaR at the conglomerate institution and to set appropriate capital requirements. The potential for conflict intensifies when the home-country bank weakens. If home regulators and/or parent managements start reporting VaR opportunistically, host managers and regulators are greatly disadvantaged. Unless and until the process is uncovered by examiners or stopped by rumor-driven deposit outflows, the parent can nontransparently transfer underwater home-country assets to its host-country sub and use the sub's good assets as collateral for debt that funds endgame gambles for resurrection. In a multiperiod model, this incremental risk-taking would expand EUDIC exposures beyond those shown in Table 7.

\section{Contractability of cross-country regulatory agreements}

In nation-based banking systems, each country works out ways for regulators and other thirdparty watchdogs to overcome weaknesses in the transparency $(\mathrm{T})$ of different bilateral contracting environments. For depositors, how transparency and contract enforcement might best be enhanced by third parties depends on the costs and effectiveness of contract provisions that discipline bank risk-taking by requiring banks to bond their promises to pay (Bonding, B) or to convey to depositors ways of punishing banks for bad performance (Deterrency, D).

For multicountry supervision to be effective, the $\mathrm{T}, \mathrm{B}$, and $\mathrm{D}$ dimensions of financial contracts must fit together in a consistent way. Regulatory vision is inevitably clouded by incentive-driven misinformation ("disinformation") that is provided deliberately either by partner regulators or by different segments of multinational banking organizations. Because disinformation seeks to evade due discipline, it differs from random errors in that its effect is negatively correlated with the implications of the adverse information it is intended to mask.

Because host-country regulators lack vision and disciplinary authority over conglomerate managers, the home-country bank and home-country regulators, the potential for conflict between hostcountry and home-country interests intensifies when one or both banks weaken. This gap in discipline 
strengthens the home-country supervisor's nationalistic incentive to delay facing up to the insolvency of an important holding company or local bank.

In a multiperiod context, supervisory forbearances give managers of the global holding company time to shift underwater assets to the host jurisdiction. Such shifting cannot be discovered by host examiners until at least the next examination. To counteract the temptation to strip assets in this way, host countries must secure improved vision and well-bonded deterrent rights.

Cross-country vision can be improved in at least two ways: by requiring safety-net managers in each nation to trade the functional equivalent of reinsurance contracts in public derivatives markets (Kane, 2005) and by negotiating agreements that strengthen individual regulators' incentives to uncover and share adverse information. Cross-country contracting might accomplish this by enhancing a country's right to collect damages from foreign bank executives (and foreign regulators) that can be shown to the satisfaction of a neutral court to have misrepresented or withheld facts whose disclosure would have helped partner-country officials to lower safety-net costs.

To control systemic risk on a Europewide basis, it is critical to countervail the way in which incentives to disinform regulators intensify when banking losses begin to multiply. One approach would be to require banking conglomerates to make their various banking subsidiaries jointly liable for losses that accrue in any EU jurisdiction. Under this form of ex post settling up, the probability distribution of stockholder returns in each bank becomes the trinomial distribution shown in Table 8. The 5-percent VaR for each bank is $\$ 920$ billion and the EUDIC would have to pony up only $\$ 160$ billion in the catastrophic event that both banks fail. In these circumstances, the expected value of the EUDIC's liability transfer is only (in billions):

$$
\mathrm{E}_{\mathrm{EUDIC}}=.0016(-\$ 160)=-\$ .256 .
$$

By making each bank hold enough capital to cover a 5\% VaR of \$920 billion, the EUDIC would shift most of the conglomerate's risk back onto the private sector. The EUDIC (and EU taxpayers) would only underwrite the risk of systemic failure, which is the kind of risk for which knock-on effects create a logical case for subsidizing banking risk across countries. 


\section{Summary implication}

Troubled banks routinely conceal unfavorable information about their performance and economic net worth. Acting on their own, bank counterparties cannot easily uncover information that is carefully concealed. Government chartering and supervision of banks and payments systems can help to enhance the transparency, bonding, and deterrency that financial contracts convey to bank counterparties. However, because banking regulation is both "other-regarding" and "other-directing," principal-agent conflicts abound.

To maximize EU welfare, the contracts under which safety-net officials are appointed must establish a second layer of transparency, bonding, and deterrency -- one that is strong enough to make country-based regulators (and the national taxpayers that back them up) accountable ex post for the opportunity costs that their activities impose on poorly informed loss-bearers in partner countries. This paper clarifies that, considered as exercises in incomplete contracting, Basel II and the EU Directive on Deposit-Guarantee Schemes fall far short of this goal.

\section{Acknowledgements}

The author wishes to thank Richard C. Aspinwall and Richard Herring for many helpful suggestions. 


\section{References}

Basel Committee on Banking Supervision. (2003, November). High-level principles for cross-border implementation of the new accord. Geneva, Switzerland.

Dangl, T., \& Lehar, A. (2000, December). Basel accord vs. value-at-risk regulation in banking. Vienna. University of Vienna. Unpublished.

Dermine, J. (2003). European banking: past, present and future. In Gaspar, V., Hartmann, P., \& Sleijpen, O. (Eds.), The transformation of the European financial system. Frankfurt: European Central Bank, 31-95.

Garcia, G., \& Nieto, M. (2006, June). Banking crisis management in the European Union: multiple regulators and resolution authorities. Journal of Banking Regulation, 6, 215-219.

Herring, R., and Schuermann, T. (2006). Capital regulation for position risk in banks, securities firms and insurance companies. In Scott, H. (Ed.) Capital Adequacy: Law, Regulation, and Implementation. Oxford: Oxford University Press.

Huizenga, H. (2005, October). The EU deposit insurance directive: does one size fit all? London: Centre for Policy Research.

Kane, E. J. (2005). Can the European community afford to neglect the need for more accountable safetynet management? Atlantic Economic Journal. Forthcoming.

Kane, E. J. (2006). Confronting divergent interests in cross-country regulatory arrangements. In Evanoff, D., \& Kaufman, G. (Eds.), Cross-border banking: regulatory challenges. Singapore: World Scientific Publishing Co.

Kupiec, P., \& O’Brien, J. (1997, December). Deposit insurance, bank incentives, and the design of regulatory policy. Washington: Board of Governors of the Federal Reserve System. Working Paper.

Schoenmaker, D., \& Osterloo, S. (2004). Cross-border issues in European financial supervision. In Mayes, D., \&Wood, G. (Eds.), The structure of financial regulation. London: Routledge.

Schoenmaker, D., \& Oosterloo, S. (2005). Financial supervision in an integrating Europe: measuring cross-border externalities. International Finance, 8, 1-27.

Schüler, M. (2003). How do banking supervisors deal with Europe-wide systemic risk? Centre for European Economic Research. Discussion Paper No. 03-03.

Smith, A. (1759). The theory of moral sentiment. Indianapolis: Liberty Classics (republished 1976).

Tversky, A., \& Kahneman, D. (1974). Judgment under uncertainty: heuristics and bias. Science, 185, 124131.

Tversky, A., \& Kahneman, D. (1981). The framing of decisions and the psychology of choice. Science, $211,453-8$.

Vives, X. (2001, February). Restructuring financial regulation in the European Monetary Union. Journal of Financial Services Research, 19, 57-82.

Zajac, E. (2006). The theory and practice of political fairness games. Tucson: University of Arizona, Department of Economics. Unpublished. 
Table 1

True distribution of individual-bank returns (in billions)

\begin{tabular}{l|l|l} 
Probability & .96 & .04 \\
\hline Variate value & $\$ 80$ & $-\$ 1,000$
\end{tabular}

Table 2

Distribution of liability transfers facing the hypothetical EUDIC when capital is zero (in billions)

\begin{tabular}{l|l|l|l} 
Probability & .9216 & .0768 & .0016 \\
\hline Variate value & 0 & $-\$ 1,000$ & $-\$ 2,000$
\end{tabular}

Table 3

Distribution of net revenue for the conglomerate banking organization (in billions)

\begin{tabular}{l|l|l|l} 
Probability & .9216 & .0768 & .0016 \\
\hline Variate value & $\$ 160$ & $-\$ 920$ & $-\$ 2,000$
\end{tabular}

Table 4

Distribution of transfers of liability facing the EUDIC if the conglomerate holds capital equal to its true 5-percent $\mathrm{VaR}$

\begin{tabular}{l|l|l} 
Probability & .9984 & .0016 \\
\hline Variate value & 0 & $-\$ 1,080$
\end{tabular}


Table 5

Distribution of perceived net revenue for the conglomerate banking organization with underreporting by both subs (in billions)

\begin{tabular}{l|l|l|l} 
Probability & .9604 & .0392 & .004 \\
\hline Variate value & $\$ 160$ & $-\$ 460$ & $-\$ 1,000$
\end{tabular}

Table 6

Distribution of perceived net revenue of conglomerate if host-country bank or regulators under-report $p$ and LGD by one-half (in billions)

\begin{tabular}{l|l|l|l} 
Probability & .9408 & .0584 & .008 \\
\hline Variate value & $\$ 160$ & $-\$ 460$ & $-\$ 1,500$
\end{tabular}

Table 7

Distribution of transfers of liabilities facing the EUDIC if conglomerate capital is set at $\$ 460 \mathrm{~B}$ because books are cooked in host country (in billions)

\begin{tabular}{l|l|l|l} 
Probability & .9216 & .0768 & .0016 \\
\hline Variate value & 0 & $-\$ 460$ & $-\$ 1,540$
\end{tabular}

Table 8

Distribution of net revenue for the conglomerate banking organization if Subsidiary banks are liable ex post for each other's losses (in billions)

\begin{tabular}{l|l|l|l} 
Probability & .9216 & .0384 & .04 \\
\hline Variate value & $\$ 80$ & $-\$ 920$ & $-\$ 1,000$
\end{tabular}

